\title{
“ARTHUR BISPO DO ROSÁRIO ESTÁ VOLTANDO": PATRIMONIALIZAÇÃO E MEMÓRIA NA INVENÇÃO DE UM PERSONAGEM ILUSTRE
}

\author{
Viviane Trindade Borges*
}

\begin{abstract}
Resumo: O presente artigo objetiva problematizar a invenção de um personagem ilustre, observando as estratégias de patrimonialização traçadas para configurar sua importância como cidadão local, instituindo-o como patrimônio. O personagem em questão é Arthur Bispo do Rosário, que por 50 anos viveu como internado em um manicômio no Rio de Janeiro em total anonimato e que após sua morte foi instituído como artista contemporâneo reconhecido nacional e internacionalmente. Em 2004, sua cidade natal, Japaratuba (SE) ergueu um memorial em sua homenagem, o qual passou a abrigar seus restos mortais. O processo que liga Bispo à Sergipe é marcado pela atribuição de novos valores, sentidos, usos e significados que procuraram conferir reconhecimento a um artista até então desconhecido em sua cidade natal, atuando diretamente na construção de um valor patrimonial que configura o personagem como lugar de memória.
\end{abstract}

Palavras-chave: Bispo do Rosário. Patrimonialização. Lugar de memória. Japaratuba. Sergipe.

\begin{abstract}
This paper aims to analyze the invention of an illustrious personage, noting how he became a cultural heritage in its hometown. The character in question is Arthur Bispo do Rosario, who lived for 50 years and hospitalized in a mental hospital in Rio de Janeiro in total anonymity and that after his death was established as a contemporary artist recognized nationally and internationally. In 2004, his hometown, Japaratuba (SE) erected a memorial in his honor, which has housed his remains. The process that connects to the

\footnotetext{
* Professora do Departamento de História da Universidade do Estado de Santa Catarina (UDESC). Pesquisadora do Laboratório de Patrimônio Cultural da UDESC e do Centro de Documentação e Pesquisa do Hospital Colônia Sant'Ana (CEDOPE/HCS-IPq).

E-mail: vivianetborges@gmail.com
} 
Bispo and Sergipe is marked by assigning new values, meanings, uses and meanings that sought to give recognition to an artist hitherto unknown in his hometown, working directly in the construction of an asset value that sets the character as a memory site.

Keywords: Bispo do Rosario. Cultural heritage. Memory sites. Japaratuba, Sergipe.

O livro "501 Grandes Artistas", de Stephen Farthing1, tem a pretensão de reunir perfis biográficos e informações relativas às obras dos "maiores artistas de todos os tempos", perpassando desde a Antiguidade clássica aos contemporâneos, englobando os mais diversos estilos e movimentos artísticos. Entre os biografados, nomes como Leonardo da Vinci, Michelangelo, Velázquez, Monet, Van Gogh, Picasso, Dalí, Duchamp, Cartier-Bresson, Jackson Pollock, Damien Hirst, Debret, Tarsila do Amaral e Di Cavalcanti e Arthur Bispo do Rosário.

O mesmo Arthur Bispo do Rosário que hoje figura entre os grandes nomes da arte, faleceu em julho de 1989, na Colônia Juliano Moreira, antigo manicômio carioca, depois de 50 anos de internamento, sem nunca ter recebido uma única visita. Seu corpo foi sepultado numa cova simples, do tipo que era destinado aos inúmeros pacientes que tiveram o mesmo fim, no Cemitério da Pechincha, em Jacarépagua, bairro da Zona Oeste do Rio de Janeiro.

O que hoje é tido como arte era por Bispo considerado um fardo, uma missão que ele era ordenado a cumprir. $O$ personagem afirmava ser Jesus Cristo e que a voz que lhe ordenava era a de Nossa Senhora, exigindo que ele cumprisse sua tarefa, ou seja, recriar o universo a espera do Juízo Final. Como resultado, ele compôs uma série de miniaturas e bordados que contavam a história do homem na terra.

Após sua morte o personagem ganhou notoriedade, suas criações passaram a ser entendidas como arte e Bispo saiu do anonimato para a consagração como artista contemporâneo. Suas obras perpassaram grandes espaços nacionais como o MAM do Rio de Janeiro, e internacionais, participando de mostras nos EUA, México, Espanha e França. O trabalho de Bispo ilustrou uma capa de $\mathrm{Cd}^{2}$, foi tema de peças de teatro ${ }^{3}$, documentários ${ }^{4} \mathrm{e}$ de um longa-metragem ${ }^{5}$, inspirou enredos e escolas de samba por todo o país ${ }^{6}$ e despertou o interesse da academia, suscitando estudos em diferentes áreas. ${ }^{7}$ Em 1994 suas criações foram tombadas pelo Instituto Estadual do Patrimônio Artístico e Cultural (INEPAC), tornaram-se patrimônio cultural do Estado do Rio de Janeiro. Em 2001 Bispo ganhou um Museu em sua homenagem dentro da 
instituição em que viveu confinado como louco, o Museu Bispo do Rosário de Arte Contemporânea, localizado nas dependências da Colônia Juliano Moreira. Em 2004, os restos mortais do personagem, que antes jaziam esquecidos no Cemitério da Pechincha no Rio de Janeiro, foram transferidos com pompas e cerimônias para sua cidade natal (antes também desconhecida), Japaratuba, no estado do Sergipe, e ganharam um túmulo suntuoso, acompanhado de um monumento em tamanho natural, digno de um herói nacional.

Objetiva-se aqui problematizar a instituição de um sergipano ilustre, observando as estratégias de patrimonialização traçadas para configurar sua importância, instituindo-o como patrimônio cultural. As estratégias de patrimonialização operam no sentido de transformar um objeto, lugar, conhecimento, ritual, modo de vida, ou mesmo um personagem, em patrimônio. Tal processo possibilita a atribuição de novos sentidos, usos e significados, aos mais diversos objetos e manifestações culturais, atuando diretamente na construção de um valor patrimonial com finalidades ligadas principalmente ao consumo dos bens culturais. No caso em questão, foi possível observar o empenho da Prefeitura de Japaratuba no intuito de patrimonializar seu artista local à fim de tornar-se uma cidade turística, investindo Bispo de significados que procuraram instituir sua sergipanidade. A patrimonialização de pessoas ${ }^{8}$, aparece aqui como a representação de determinado discurso patrimonial, responsável pela configuração do personagem como lugar de memória, elo entre o passado e o futuro.

\section{A INVENÇÃO DE UM PERSONAGEM ILUSTRE}

Em janeiro de 2004, uma reportagem do Jornal Cinform ${ }^{9}$, de Aracaju, trazia a seguinte manchete: "Arthur Bispo do Rosário está voltando". Foi com muita "pompa e honra" que os restos mortais daquele instituído como um "sergipano ilustre" retornaram à sua terra natal. A iniciativa coroou os esforços da Prefeitura de Japaratuba, que em 1998 editou uma portaria nomeando um procurador, o então vereador Otávio Leite, para localizar os restos mortais de Bispo. Segundo um periódico local:

O processo foi demorado, cheio de burocracia, mas neste domingo, dia 04.01, os restos mortais do artista sergipano chegou [Sic] com honras a Aracaju e seguirão para a sua terra natal, Japaratupa. [...] Após identificados e liberados, os restos mortais do sergipano ilustre Artur Bispo do Rosário foram transferidos para a cripta da catedral metropolitana do Rio de Janeiro, no último dia 19, onde foi celebrada uma missa de pompa e honra, ato raro, na igreja, contando com 
a presença de gente ilustre da arte e da política nacional. A urna com os restos mortais continua na catedral do Rio e chega a Aracaju neste domingo, pelo vôo da Varig, às 13 horas. O prefeito de Japaratuba, Gerald Olivier, viajou ao Rio de Janeiro para conduzir a urna com os restos mortais ${ }^{10}$.

A data escolhida para receber a urna funerária com as cinzas de Bispo foi durante o $3^{\circ}$ Festival de Artes da cidade, o qual acontece simultaneamente com a Festa de Santos Reis e São Benedito. Tal evento ocorre anualmente na primeira semana de janeiro, e faz referencia ao dia de louvação dos reis magos, juntamente com os louvores à santos católicos consagrados como santos negros, como Nossa Senhora do Rosário e São Benedito, envolvendo a participação de grupos folclóricos locais.

AFesta de Santos Reis foi inventariada no município de Laranjeiras (SE), vizinho à Japaratuba, através do sistema Inventário Nacional de Referencias Culturais (INRC), desenvolvido pelo Instituto do Patrimônio Histórico e Artístico Nacional (IPHAN). Esse instrumento atua desde 2000 na produção de conhecimento relativo ao patrimônio imaterial, dando origem a inventários em todas as regiões do país. Trabalhando com categorias instituídas pelo Decreto 3.551/2000, o INRC objetiva dar conta do processo de produção desses bens, apreendendo os valores neles investidos, sua transmissão e reprodução, não esquecendo as condições materiais de produção. ${ }^{11}$

O Inventário Nacional de Referências Culturais do Município de Laranjeiras, no Estado de Sergipe, foi realizado entre os anos de 2008 e 2009 e incluiu as localidades de Mussuca, Quintalé, Pastora, Bom Jesus, Vila do Faleiro, Povoado Machado. Finalizado na primeira etapa do INRC - Levantamento Preliminar - o inventário procura atender à diretriz da política de inventários que propõe a investigação das referências culturais de populações que residem em municípios com centros históricos tombados. ${ }^{12}$

Japaratuba, provavelmente por não ter um centro histórico tombado, foi excluída do Inventário, mas têm na Festa de Santos Reis uma de suas principais atividades culturais. Há dez anos o evento tornou-se uma celebração ainda maior, passando a homenagear aquele instituído como seu mais ilustre personagem, Arthur Bispo do Rosário.

Artur Bispo do Rosário volta à Sergipe. Amanhã, ao meio-dia, a urna funerária contendo seus restos mortais chega a Aracaju, juntamente com quatro obras do artista, 
acontecimento que dá o pontapé inicial para a $3^{\mathrm{a}}$ edição do Festival de Artes da cidade de Japaratupa. ${ }^{13}$

No processo de invenção do artista japaratubense, intencionava-se tornar Bispo conhecido regionalmente a qualquer custo. Nesta perspectiva, o Festival de Arte local que ocorria simultaneamente à Festa de Santos Reais, passou a se chamar "Festival de Arte Bispo do Rosário". No trabalho de produção de um passado que servisse ao presente (e ao futuro), Bispo foi inventado como artista local e inserido nos festejos tradicionais. Assim, a cidade alimenta e recria anualmente a monumentalização do personagem, através do culto à sua personalidade ou, mais precisamente, do culto a uma determinada imagem de Bispo: aquela que o inscreve nas tradições coletivas locais, de forma a atestar sua sergipanidade.

No dia em que Bispo retornou a sua cidade natal, diversos moradores de Japaratuba se perguntavam: "quem seria esse tal de Bispo que todos estão comentando? O que teria feito de tão importante para merecer uma estátua?" Muitos acompanhavam os festejos que, com estardalhaço, introduziam a urna funerária na cidade, sem saber quem era o ilustre desconhecido:

Maria Antônia, 63 anos, saiu cedo de casa para não perder nenhum detalhe. Às $16 \mathrm{~h}$ em ponto - quando chegaria a comitiva que acompanhou a urna em carro do Corpo de Bombeiros - ela estava no memorial. O atraso de uma hora deixou tempo para observar o movimento dos grupos folclóricos que se concentravam no local para saudar o artista. Assim como ela, porém, muitos ainda se indagavam quem havia sido aquele homem da estátua. "Ainda não encontrei ninguém que me dissesse que ele é", queixava-se. Bispo, na verdade, é popular entre os eruditos. ${ }^{14}$

Famoso entre críticos de arte do Brasil e do exterior, desconhecido entre seus conterrâneos, esta era a situação paradoxal do Bispo consagrado por seu gênio artístico cuja ligação com a cidade natal sempre fora objeto de poucas certezas e muitas especulações. No processo de patrimonialização, uma das tarefas da museóloga Fabiana Carnevale Maciel, na época responsável pelo trabalho de restauração de suas peças na Colônia Juliano Moreira, foi tentar buscar as origens biológicas do personagem, investigando a existência de familiares deste em Japaratuba. Segundo ela, "em todos os dados sobre Arthur Bispo, a informação é de que não existem registros de parentes, mas isso não quer dizer que eles não existam"15. Descobrir a existência de familiares possibilitaria reforçar os vínculos "sanguíneos" que a Prefeitura da cidade procurava estabelecer. Contudo, até hoje a única ligação concreta 
do personagem com a cidade é um registro no Livro de Batismo da Igreja de Nossa Senhora da Saúde, igreja matriz de Japaratuba: "Aos 5 de outubro de 1909 baptisei solemnemente Arthur, com 3 meses, legítimo de Claudino Bispo do Rosário e Blandina Francisca de Jesus. Foram Padrinhos Maximiniano Ribeiro dos Santos e Cândida dos Prazeres".

O translado da urna funerária do "homem da estátua" custou R\$ $1.728,00$ ao Município. O empenho em trazer o personagem não tinha apenas como objetivo homenagear o filho ilustre, mas fazia parte da estratégia de patrimonialização que pretendia tornar Japaratuba uma cidade turística:

Jornalistas de várias partes do país virão a Japaratuba. Acreditamos que esse seja o primeiro passo para colocar a cidade no roteiro turístico nacional.

A empreitada [...] promete incrementar o turismo na cidade, mas ciente de que Bispo ainda é um estranho para a maioria dos populares. ${ }^{16}$

O discurso do turismo se encarregou de preencher, com seus argumentos econômicos, o vazio de sentido, entre a população japaratubense, da invenção de Bispo como monumento em sua cidade natal. Nas falas relacionadas a esses acontecimentos, a volta do "artista genial", "estranho para a maioria dos populares", é configurada a partir da clara intenção de usar o seu prestígio para tornar a pequena cidade um local turístico, possibilitando o aproveitamento dos benefícios materiais e simbólicos advindos desta condição.

$\mathrm{Na}$ configuração dessa estratégia de patrimonialização, foram engendradas práticas diversas. Primeiramente foi erguido um monumento, uma estátua em tamanho natural, inaugurada em 2002, local onde a urna funerária foi depositada em 2004. Também foi construído um memorial e atualmente cogita-se da possibilidade de edificação de um Museu em homenagem a Bispo. ${ }^{17}$

A configuração dessa tessitura que inventa Bispo como monumento de Japaratuba se parece com aquela que envolveu o artista plástico Horácio Hora, o qual teve seus restos mortais transferidos do cemitério Père Lachaise, de Paris, onde permaneceram por quase 100 anos, para a cidade sergipana de Laranjeiras. Apesar da pompa que cercou o evento, o túmulo hoje se encontra esquecido. O pintor, que morreu jovem, aos 37 anos, fez sua carreira na França, deixando uma obra muito pequena que hoje pertence ao Museu Histórico de Sergipe. A transferência visava consolidar Hora "como o mais importante e expressivo pintor sergipano da história cultural sergipana dos últimos dois séculos. O artista nasceu na cidade de Laranjeiras em 1853 e faleceu em Paris, no ano de 1890137". Contudo, "a troca não foi o que se pode chamar de um 
sucesso", visto que ainda hoje, para grande parte da população de Laranjeiras, "Hora é um desconhecido". ${ }^{18}$

Investigar a patrimonialização de Bispo como cidadão japaratubense é problematizar o trabalho de enquadramento que possibilitou a solidificação de uma determinada memória coletiva. A ideia de memória coletiva enquanto coerção, ou seja, como algo imposto por determinado grupo social, é tributária da perspectiva apontada por Michel Pollack que, apoiado em Bourdieu, a define (a memória coletiva) como "uma forma específica de violência simbólica"19. Uma dessas práticas foi a elaboração de um projeto de "conscientização" junto às escolas, não apenas as de Japaratuba, mas de todo o Estado do Sergipe, com o uso de uma cartilha educativa sobre o personagem, enfocando sua trajetória de superação dentro da Colônia Juliano Moreira e sua ascensão como artista, o que atesta o caráter verdadeiramente pedagógico - de levar à imitação pelo exemplo - da iniciativa. Previa-se a distribuição do material nas escolas, juntamente com a realização de apresentações teatrais voltadas ao público infantil. Outro fato ilustrativo da capilaridade deste discurso que institui Bispo como "herói local" ocorreu no bairro de São Conrado, em Aracaju, onde uma escola municipal recebeu o nome do "artista": "Escola Municipal Arthur Bispo do Rosário".

Neste processo de instituição de significados, tornam-se recorrentes as referencias à trajetória de superação do personagem. Tais falas delineiam um indivíduo que, mesmo internado em um hospício, conseguiu criar uma "obra de rara beleza", a qual permitiu sua consagração como "artista internacionalmente conhecido" 20 . Esta invenção do passado pode ser interpretada na mesma perspectiva proposta por Delgado. ${ }^{21}$ No processo de constituição de conteúdos para o passado, o investimento para solidificar e dotar de duração e estabilidade uma determinada memória para representar o conjunto da sociedade configura operações de seleção, organização e uniformização da multiplicidade de significados atribuídos ao passado.

Bispo é, então, instituído como sergipano, filho ilustre de Japaratuba por um determinado grupo detentor do controle dos lugares de memória locais, através da imposição de significados que, de forma autoritária, são configurados como cristalizadores da memória coletiva da cidade. Produz-se, assim, um determinado passado para Bispo, operando sua patrimonialização, enfocando seu local de nascimento e sua importância enquanto artista plástico consagrado nacional e internacionalmente. Em tal enquadramento, confere-se pouca importância aos 50 anos em que ele viveu no abandono e anonimato na Colônia Juliano Moreira, destacando-se apenas sua genialidade artística e, em tom edificante, sua superação pessoal.

Para que fosse possível a invenção do ilustre sergipano, filho de Japaratuba, buscou-se obter o reconhecimento da comunidade local através 
de discursos que articulam a trajetória de superação do personagem à sua importância no mundo das artes plásticas. Segundo o site oficial do Município: ${ }^{22}$

O trabalho da prefeitura em trazer Bispo de volta à Japaratuba é um resgate da história do município e as pessoas precisam saber o quão importante ele foi para as artes plásticas contemporâneas, não só pelo seu trabalho, mas por ser negro e pobre", conta o secretário de Cultura [...]

De acordo com o prefeito a volta de Bispo do Rosário a Japaratuba significa uma valorização da cultura popular Japaratubense e um reforço para os jovens do município. "A mensagem que ele traz é paz, de superação, pois ele criava a partir do nada, e com isso se transformou, mesmo sem perceber, em um exemplo para seus jovens conterrâneos." ${ }^{23}$ Tal discurso deveria ser capaz de motivar os seus conterrâneos, sobretudo os jovens - talvez pobres e negros como Bispo - a seguirem seus exemplos de luta e superação. Nesse enfoque, conforme Enders: ${ }^{24}$

A biografia permite, [...] uma reconstituição viva do passado, mas esta não é sua única, missão pedagógica. É também sua missão difundir vidas exemplares. O exemplo do grande homem deve ser contagioso, fazer surgir novos exemplos ou, ao menos, servir de guia moral ou cívico.

Evidencia-se, pois, a função moral do monumento que se edificava. Como salientou Le Goff, o monumento deve "iluminar" e "instruir". ${ }^{25}$ No caso em tela, a narrativa das autoridades de Japaratuba sobre Bispo tem um tom francamente hagiográfico, constituindo-se em um "discurso das virtudes", ao retomar antigas tradições do gênero biográfico: Durante muito tempo, da Antiguidade à época moderna, o gênero biográfico teve por função essencial identificar. Prestou-se ao discurso das virtudes e serviu de modelo moral edificante para educar, transmitir os valores dominantes às gerações futuras. O gênero biográfico participa, pois, de um regime de historicidade no qual o futuro é a reprodução dos modelos existentes, que devem perpetuar-se. ${ }^{26}$

A configuração discursiva foi imposta através da repetição de determinados enunciados, os quais instituem o filho ilustre de Japaratuba que saiu do anonimato e do isolamento da loucura, e ganhou os grandes espaços consagrados às artes plásticas, tornando-se um "artista genial". Era esta a "biografia" de Bispo que deveria ser conhecida e aceita por seus conterrâneos. Com isso, objetivava-se solidificar uma determinada memória a seu respeito, através da seleção de certas características e significados que lhe atribuíam alguns valores humanos e culturais, permitindo que a comunidade local 
confirmasse, por meio dele, a sua própria identidade. Ou seja, ao contar - para si e para os outros - a história de Bispo, Japaratuba contava a sua própria história. Confirma-se assim sua patrimonialização, engendrando uma totalidade discursiva relacionada a conceitos como humanidade e identidade.

A invenção de Bispo como monumento japaratubense foi acompanhada por uma museóloga, citada anteriormente. O discurso da museóloga, ancorado em um poder-saber específico, articula-se aos discursos que procuravam inventar o artista local, autorizando o projeto de patrimonialização. A proposta fazia parte de um plano maior, que objetivava, através do prestígio trazido pelo "retorno" de Bispo, "avaliar e revitalizar todo o patrimônio histórico do Estado" e, para isso, a museóloga era considerada uma "peça chave". ${ }^{27}$

Foi a partir desse processo de imputação de significados que na cidade onde praticamente ninguém sabia quem fora Arthur Bispo do Rosário, uma estátua foi erguida em sua homenagem na entrada principal do núcleo urbano, em 11 de junho de 2002. Conforme colocado anteriormente, em 2004, o monumento foi reinaugurado e passou a abrigar a urna funerária de Bispo. $\mathrm{Na}$ perspectiva de tornar o local um ponto turístico e um marco de referência para a comunidade local, é significativa a inscrição carregada de orgulho colocada aos pés do monumento: "Pise forte neste chão, Arthur Bispo do Rosário está de volta". A estátua mostra Bispo altivo em seu traje mais consagrado: o "manto da apresentação". Envergando a veste que usaria para ascender aos céus no dia do Juízo Final, o personagem lembra um profeta, gesticulando ao proferir suas sábias palavras. A imagem em nada remete à figura de um esquizofrênico paranoide, que durante meio século viveu internado numa instituição psiquiátrica, bem longe de sua terra natal.

Ainda que para alguns a estátua não passasse de um "modesto monumento" que mais parecia um "suporte para amarrar animais"28, sua inauguração possibilitava a patrimonialização do personagem através da perpetuação de sua memória (ou de uma determinada memória), ligando este, inseparavelmente e sem escapatória, ao Estado do Sergipe e a cidade de Japaratuba, ainda que Bispo nunca tenha feito referências públicas à sua vida no local. De acordo com Le Goff: 29 "o monumento tem como características o ligar-se ao poder de perpetuação, voluntária ou involuntária, das sociedades históricas (é um legado à memória coletiva) [...]”.

$\mathrm{Na}$ tessitura que patrimonializa o personagem, procuram-se justificativas para a ausência de Japaratuba nas falas de Bispo, visto que ele nunca teria mencionado o nome da cidade publicamente. Neste sentido, visto que, como Jesus Cristo, ele não poderia afirmar ter raízes em lugar algum:

Mesmo nunca tendo falado na cidade em que nasceu, Bispo é alvo de elogios rasgados por parte dos conterrâneos. 
Como se identificava como Jesus Cristo, Bispo não admitia ter raízes fincadas em lugar algum. A justificativa é tão aceita que no obelisco erguido em sua homenagem chama a atenção a frase: "Pise forte neste chão. Você está na terra de Arthur Bispo do Rosário". ${ }^{30}$

No processo de imortalização de Bispo como artista japaratubense, patrimônio cultural da cidade, a invenção de memórias póstumas objetiva "parar o tempo, bloquear o trabalho do esquecimento, fixar um estado de coisas, imortalizar a morte, materializar o imaterial para apreender o máximo de sentidos num mínimo de sinais". ${ }^{31}$ Assim, como filho ilustre daquela terra, o personagem foi entrelaçado por uma teia de significados que engendra em "tradições" e "costumes" locais. Desta forma, intenciona-se fazer ver em suas peças traços que remetem à suas origens sergipanas, como as festas religiosas, citadas anteriormente e a tradição dos bordados.

Nessa tentativa de inventar as origens de Bispo, as tradições integrantes do universo cultural da região, tais como o rendendê, o ponto cruz e o crivo em linho, além de rendas, tricôs, crochês e tecelagem, transmutam-se discursivamente em "influências" presentes nas suas criações. Toda essa riqueza cultural foi inventariada em Laranjeiras através do INRC, juntamente com a Festa de Santos Reis, e fazem parte do artesanato de Japaratuba. Na tentativa de mostrar as influencias de tais costumes nas criações de Bispo, o "Manto da Apresentação", tido como uma das peças mais importantes por ele realizadas, é exibido como reflexo desta cultura popular que o personagem teria abandonado aos 15 anos de idade, mas que estaria impregnada à sua visão de mundo para sempre. Assim, os bordados e todo o colorido cultural da região são delineados como as origens sergipanas de Bispo e legitimam seu retorno a Japaratuba.

Em 2009, ocasião em que foi celebrado os cem anos de Bispo, ocorreram as filmagens do longa-metragem "O senhor do Labirinto". O filme insere definitivamente Bispo na tradição dos bordados do Sergipe. O programa "Ação", exibido pela TV Globo em 21 de novembro de 2009, mostrou as oficinas de criação das réplicas das peças do "artista" usadas nas filmagens. ${ }^{32}$ As bordadeiras que confeccionaram o material, acostumadas com o rendendê e o ponto cruz, desenvolveram uma nova técnica que passou a ser chamada de "ponto Bispo", um trabalho delicado que produz um ponto em alto relevo.

O bispo fazia um caseado, ele juntava as bolinhas e isso criava um relevo, que dava mais nitidez ao que ele tava escrevendo. Por isso que a gente chama de Ponto do Bispo, porque ele também desenvolveu algo em cima daquela técnica, pequena técnica que ele detinha", explica Everlane Santos, assistente das oficinas. 
O "ponto Bispo" está sendo usado em outros trabalhos, como a confecção de bolsas e guardanapos que levam o nome do ilustre japaratubense, estimulando o artesanato ligado ao turismo local. A ideia é tornar o ponto tão conhecido quanto a renda irlandesa, que garante o sustento de muitas famílias da região. Em 2009, a renda irlandesa produzida em Divina Pastora (SE) recebeu o título de Patrimônio Cultural do Brasil.

O modo de fazer Renda Irlandesa produzida em Divina Pastora (SE) foi incluído no Livro de Registro dos Saberes. O município surge como principal território da renda irlandesa porque no local se encontraram os elementos que culminaram com a apropriação do ofício (vinculado originalmente à aristocracia) por mulheres humildes que reinventaram a técnica, o uso e o sentido deste saber-fazer. ${ }^{33}$

Bispo foi então reverenciado por ter tornado à técnica usada nos bordados da região conhecida "mundialmente", incitando a admiração das bordadeiras e o desejo de que ele fosse valorizado em sua cidade natal "A parte do ponto corrente, eu aprendi já ainda pequenininha, só que eu não sabia que tinha esse significado. Hoje se expandiu praticamente mundialmente, através de Arthur Bispo do Rosário. Todos os desenhos, todos os bordados dele se resumem no pontinho de corrente", diz a artesã Maria José da Silva. "Eu gostaria de deixar o trabalho de Arthur Bispo na terra dele bem divulgado e valorizado, porque lá fora a gente sente que o pessoal valoriza muito", conta a bordadeira Maria da Silva Pereira.

Japaratuba ficou com as cinzas de Bispo, Rio de Janeiro com suas criações. Os sete anos de disputa entre as duas cidades pelos restos mortais do personagem finalizaram com o seguinte acordo: enquanto a localidade sergipana abrigaria a urna funerária, as peças tombadas pelos INEPAC permaneceriam no Museu Bispo do Rosário, na Colônia Juliano Moreira:

O Secretário da Cultura, José Carlos Teixeira, foi ao Rio de Janeiro especialmente para tratar da vinda da urna funerária de Arthur Bispo do Rosário para a cidade de Japaratuba, onde um memorial será construído pela Prefeitura para abrigar o máximo de referências à obra de Bispo, já que nenhuma peça será cedida, uma vez tombadas e pertencentes ao Ministério Público. ${ }^{34}$

Nenhuma das peças tombadas pelo Patrimônio Histórico do Rio de Janeiro e pertencentes ao Ministério Público foi cedida a Japaratuba. "Para trazê-las, a Secretaria de Cultura terá que entrar num acordo com o Governo 
carioca, que se comprometeu em emprestar algumas peças mediante assinatura de um seguro" 35 , como aconteceu por ocasião da celebração pela transferência dos restos morais do "artista":

Bispo não veio sozinho. Cinco de suas obras ficaram, até ontem, domingo, 11, em exposição no Centro Dona Janoca, em Japaratuba. Pela primeira vez em Sergipe, as peças chamaram atenção pela riqueza de detalhes e utilização de materiais inusitados, como sucatas, madeiras e retalhos. ${ }^{36}$

Em 2009, no VIII Festival de Arte Arthur Bispo do Rosário, o anúncio da criação do museu e da produção do filme em sua homenagem marcou o suposto centenário do nascimento do personagem e os 20 anos de sua morte. Tais discursos enredam Bispo a Japaratuba, entrelaçando sua existência e sua "obra" à história do Município, que então completava 150 anos.

Frente à obsessão comemorativa e a emergência da memória como uma das preocupações políticas e culturais das sociedades contemporâneas ${ }^{37}$, as comemorações dos centenários de nascimento e morte ganham relevância especial, evocando personalidades de um passado que se quer perpetuar. A celebração destes aniversários "redondos" foi considerada a ocasião "perfeita" para anunciar a criação do novo espaço museológico. O objetivo era "construir o Museu Arthur Bispo do Rosário em Japaratuba", aproveitando algumas réplicas de seus objetos que foram confeccionadas no Estado, por ocasião das filmagens de "O Senhor do labirinto". O filme, inspirado na biografia escrita pela jornalista Luciana Hidalgo ${ }^{38}$, foi rodado na localidade sergipana em 2009, e contou com oficinas realizadas por bordadeiras que reproduziram algumas das criações de Bispo.

O longa-metragem marcou as comemorações que envolviam o nascimento e a morte do personagem em rituais de celebração, os quais procuravam reiterar certas lembranças, enquadrar determinadas memórias, fortalecendo os vínculos de Bispo com sua cidade natal e procurando apoio na comunidade para engendrar definitivamente sua patrimonialização. A produção obteve apoio da Prefeitura de Japaratuba e do Governo do Estado do Sergipe.

Um dos primeiros parceiros a incentivar que as filmagens fossem realizadas em Sergipe foi o Governo do Estado. Através do Programa de Apoio Cultural desenvolvido pelo Banese, foram investidos R $\$ 500$ mil na produção do filme. Em outro convênio, através do Fundo Estadual de Patrocínio de Projetos de Comunicação Social, da Secretaria de Comunicação, o investimento chegou a R\$ 270 mil. Os enunciados desencadeados pela referida produção cinematográfica enredam, misturam e acabam por submergir Bispo nas 
tradições sergipanas, mostrando a maneira como a região produziu seu "artista", buscando desvendá-lo em função de suas supostas origens.

Conforme a figurinista Simone Aquino:

O que vai ficar para Sergipe é a vida de Arthur Bispo do Rosário. Desde que ele morreu, a obra dele foi para Europa, foi para o mundo intelectualizado, para o mundo cult. Depois trouxemos Arthur Bispo para a raiz e reproduzimos a história para voltar ao mundo com a nossa visão sergipana e brasileira. Trazer a arte de Bispo do Rosário para Sergipe é desvendar vários códigos na obra dele que nós não desvendávamos. Foi conhecendo a cultura dele, de onde ele veio que a gente consegue entender melhor toda a criação $[\ldots] \cdot{ }^{39}$

No Rio de Janeiro, o Museu Bispo do Rosário também celebrou os aniversários de nascimento e morte de seu artista, disputando com Japaratuba as glórias associadas ao personagem: "No Rio, Cesar Maia brada que Arthur é nosso! E deseja capitanear todas as glórias". ${ }^{40}$ A exposição "Beleza", realizada na Juliano Moreira, procurou novamente ligar as criações de Bispo às produções artísticas contemporâneas, reforçando a trama discursiva que procura instituí-lo "apenas" como "artista", e não como "artista louco".

Conforme a antropóloga Regina $\mathrm{Abreu}^{41}$, muitas vezes os mortos tornam-se mercadorias a serviço de determinadas causas. A autora cita como exemplo deste fato alguns defuntos ilustres que são momentaneamente ressuscitados pela mídia através de filmes e comerciais de TV, como aconteceu com o poeta Vinícius de Moraes, o qual, por meio das novas tecnologias, pôde ser visto tomando cerveja com seu parceiro, Tom Jobim, decorridos alguns anos de seu falecimento. De forma semelhante, Bispo também foi ressuscitado. As comemorações e o filme realizados em Japaratuba, bem como a exposição efetuada na Colônia Juliano Moreira, constituem elogios fúnebres agenciados por formas modernas de lembrar os mortos.

$\mathrm{Na}$ mesma perspectiva, a estátua que recepciona os visitantes em Japaratuba torna o morto uma mercadoria a serviço do turismo local. Ainda segundo Abreu:

A evocação dos mortos associou-se também a outras formas de culto e visitação, além da visita ao túmulo no cemitério ou da veneração de relíquias. Conferências, pronunciamentos de elogios póstumos, rituais religiosos, lançamentos de biografias, exposições comemorativas em museus e até 
programas especiais de televisão são algumas das formas modernas de "lembrar os mortos". ${ }^{42}$

As comemorações de nascimento e falecimento "promovem a celebração da imortalidade do monumento". ${ }^{43}$ Celebrar a morte confere ao falecido uma espécie de imortalidade. Falar, por meio de palavras e imagens, sobre o morto; relatar sua trajetória, seus feitos, suas conquistas, é uma maneira de perpetuar sua passagem pela Terra. Celebrações como essas acabam cristalizando verdades sobre a trajetória do sujeito extinto. No caso de Bispo, a produção de um filme baseado em uma das biografias mais conhecidas escritas sobre ele reforça determinada enunciação a seu respeito, contribuindo para aumentar a popularidade do sergipano negro e pobre que, contra tudo e contra todos, alcançou a consagração artística internacional.

No trabalho de patrimonialização do artista japaratubense, diferentes enunciados se articulam, tecendo a batalha discursiva que transforma Bispo em monumento à cultura local. De acordo com Tedesco:

Os monumentos são sempre mediadores de memória. Glória, fama, alegoria, valor cultural, social e político, histórico, controle social, poder, regionalismo, aspirações políticas... são algumas das expressões mediadas pelo monumento à memória. ${ }^{44}$

A patrimonialização de Bispo foi (e continua sendo) possibilitada por um trabalho de enquadramento da memória operado por determinados grupos interessados na invenção do artista japaratubense. Tornar a pequena cidade um local turístico e revitalizar o patrimônio cultural do Estado do Sergipe eram (e são) os principais objetivos daqueles que organizaram a volta póstuma de Arthur Bispo do Rosário à sua terra natal. Nesta batalha discursiva, foram ressaltadas a história de superação do louco anônimo que se tornou internacionalmente conhecido por sua arte e as "influências" das tradições locais presentes em suas criações. Ao longo desse processo, procurou-se criar os elementos necessários para que a comunidade local se orgulhasse de seu conterrâneo mais ilustre, buscando transformá-lo em um espelho de sua identidade.

A patrimonialização de pessoas, como tentativa de representar determinado discurso patrimonial é sintoma de um presente obcecado pela configuração de lugares de memória. Observa-se um desejo de historização imediata, que provoca a produção e circulação de passados esquecidos, ocultos ou simplesmente inventados, sob a perspectiva de que "rememorar, não esquecer é apresentado como um dever pessoal dirigido a cada um de nós". ${ }^{45}$ 
Procura-se, seleciona-se, indica-se no passado o que deve ser retido para assim preparar o futuro. Institui-se lugares materiais, simbólicos, funcionais, investidos de uma aura de significados ligados a afetividade, pertencimento e perpetuação, enfim, lugares de memória. Foi desta forma que Japaratuba apreendeu Bispo, procurando enfatizar seu gênio artístico, reconhecido nacional e internacionalmente, percebendo traços da cultura local em suas criações e destacando sua trajetória como exemplo de superação. Tal processo engendrouse através da construção do personagem enquanto lugar de memória, construído pela intervenção de determinados agentes sociais que assumiram a posição de investir de significados ligados a identidade e as tradições locais, um sujeito até então desconhecido em sua cidade natal. A patrimonialização de Bispo representa determinado discurso patrimonial que estabelece a ligação entre passado e futuro, tornando o personagem lugar de memória.

\section{NOTAS}

${ }^{1}$ FARTHING, Stephen. 501 Grandes Artistas. Rio de Janeiro: Editora Sextante, 2010.

2 Refiro-me à capa do CD Severino, do grupo Paralamas do Sucesso (1994).

3 Peças teatrais como, "Bispo Jesus do Rosário - A via sacra dos contrários" (de Clara Góes, 1999), "Senhor dos labirintos" (do Grupo Imbuaça, 2000), "Bispo" (de João Miguel, 2004) e "Andanças - Vida e Obra de Arthur Bispo do Rosário" (de Alex Mello, 2007).

4 Arthur Bispo do Rosário. Filme documentário de curta metragem. Direção: Fernando Gabeira, 1985. Biblioteca do Instituto de Psiquiatria da UFRJ; O Bispo do Rosário. Direção e produção: Helena Rocha e Miguel Przewodoski, 1993. Biblioteca do Instituto de Artes da UFRGS; $O$ prisioneiro da passagem. Filme documentário de curta metragem. Direção: Hugo Denizart. Produção do Ministério da Saúde, 1982. Acervo do Instituto Municipal de Assistência à Saúde Juliano Moreira, RJ.

5 Em 2009 começaram as filmagens de "O Senhor do labirinto", produção cinematográfica sobre a vida de Arthur Bispo do Rosário, baseado na biografia de mesmo título escrita por Hidalgo (1996). Bispo será interpretado pelo ator Flávio Bauraqui (Zero Hora, 02/03/2008).

6 Em 1997, A Unidos do Porto da Pedra, do Grupo especial A do Rio de Janeiro, cantou o samba enredo "No Reino da Folia, Cada Louco com a sua Mania", o qual homenageava, entre outros "loucos", Bispo do Rosário. Em 2005, a Escola de Samba Alegria da Zona Sul, do Rio de Janeiro, do Grupo de Acesso B, apresentou uma fantasia inspirada no "Manto da Apresentação". No ano seguinte, a Escola Acadêmicos de Niterói, de Canoas, no Rio Grande do Sul, venceu o carnaval local apresentando "a história do artista plástico Arthur Bispo do Rosário que havia morrido em um hospital psiquiátrico no Rio de Janeiro”. O enredo era "Arthur Bispo do Rosário, o labirinto de uma vida". Em 2007, o Grêmio Recreativo Cultural Escola de Samba Vila Nova, do Grupo Especial do litoral paulista, também contou a história do personagem, "tido como uma das maiores expressões do país, e também fora dele, em sua arte". Bispo foi lembrado ainda no carnaval de 2007, como "um mestre das artes plásticas brasileiras", pela Escola de Samba Império Serrano, do Grupo Especial A, do Rio de Janeiro, 
cujo tema era "Ser diferente é normal: o Império Serrano faz a diferença no carnaval". Bispo também ganhou destaque no carnaval de 2010, na Escola de Samba Acadêmicos do Cubango, do Grupo de Acesso A, do Rio de Janeiro. A Escola abordou os 158 anos do antigo prédio do Hospital Nacional de Alienados da Praia Vermelha, anteriormente chamada de "Praia da Saudade", localizado na Avenida Pasteur, Bairro da Urca, no Rio de Janeiro. Entre outros aspectos, foram destacados alguns personagens famosos que passaram pelo antigo manicômio carioca, como Lima Barreto, João Cândido e Arthur Bispo do Rosário (BORGES, Viviane Trindade. Do esquecimento ao tombamento: a invenção de Arthur Bispo do Rosário. Tese (Doutorado em História), Porto Alegre: UFRGS. 2010, p. 155).

7 Cabe citar aqui os estudos acadêmicos localizados até o presente momento a respeito de Bispo: BORGES, Viviane Trindade. Do esquecimento ao tombamento: a invenção de Arthur Bispo do Rosário. Tese (Doutorado em História), Porto Alegre: UFRGS, 2010; AQUINO, Ricardo. Museu Bispo do Rosário: criação e resistência. Dissertação (Mestrado em Memória Social e Documento), Rio de Janeiro: UNI-RIO, 2004; BURROWES, Patrícia. O universo segundo Arthur Bispo do Rosário. Rio de Janeiro: Editora FGV, 1999 (a publicação originouse da dissertação de mestrado da autora, em Comunicação e Cultura na UFRJ); CORRÊA, Denise. Arthur Bispo do Rosário: sua trajetória como artista plástico. Dissertação (Mestrado em História da Arte), Rio de Janeiro: UFRJ, 2000; DANTAS, Marta. Arthur Bispo do Rosário: a estética do delírio. Tese (Doutorado em Sociologia), Araraquara: UNESP, 2002; FARIA, Orlando da Rosa. O segredo do labirinto: uma proposta de leitura da obra plástica de Arthur Bispo do Rosário. Dissertação (Mestrado em História). Rio de Janeiro: PUC-RJ, 1996; MARTINS, M. C. Amado. Arthur Bispo do Rosário, o artista e seus estandartes. Dissertação (Mestrado em Artes Plásticas), Rio de Janeiro: UFRJ, 1992; PASSOS, David Oliveira. Arthur Bispo do Rosário: o artista, o delirante místico, o caso clínico da psiquiatria. Rio de Janeiro, s/e (monografia apresentada à FIOCRUZ - Escola Nacional de Saúde Pública, s/d); SILVA, Jorge Anthonio e. Arthur Bispo do Rosário. Tese (Doutorado em Comunicação e Semiótica), São Paulo: PUC/SP, 1997.

8 A expressão “patrimonialização de pessoas" foi usada por Regina Abreu (ABREU, Regina. "Tesouros vivos" ou quando as pessoas transformam-se em patrimônio cultural - notas sobre a experiência francesa da distinção do "Mestre de Arte". In: ABREU, Regina. CHAGAS, Mário. Memória e patrimônio, ensaios contemporâneos. Rio de Janeiro: FAPERJ, 2003, p. 90) no texto "Tesouros vivos" ou quando as pessoas transformam-se em patrimônio cultural-notas sobre a experiência francesa da distinção do "Mestre de Arte".

9 Arthur Bispo do Rosário está voltando. CINFORM, Cultura e Variedades. Aracaju, 04/01/2004.

${ }^{10}$ Correio Urbano, Aracaju, 05/01/2004.

${ }^{11}$ Grande parte dos Inventários já está disponível no site do IPHAN na Internet (www.iphan. gov.br), outros ainda estão em fase de preenchimento. Ver ainda: (SANT'ANNA, Marcia. A face imaterial do patrimônio cultural: os novos instrumentos de valorização. In: ABREU, Regina. CHAGAS, Mário. Memória e patrimônio, ensaios contemporâneos. Rio de Janeiro: FAPERJ, 2003).

12 www.iphan.gov.br. Acesso em 21/01/2010.

${ }^{13}$ Correio Urbano, Aracaju, 05/01/2004.

${ }^{14}$ Arthur Bispo do Rosário está voltando. CINFORM, Cultura e Variedades. Aracaju, $04 / 01 / 2004$. 
${ }^{15}$ CINFORM, Cultura e Variedades. Aracaju, 20/07/2003.

${ }^{16}$ Arthur Bispo do Rosário está voltando. CINFORM, Cultura e Variedades. Aracaju, 04/01/2004.

${ }^{17}$ Arthur Bispo do Rosário está voltando. CINFORM, Cultura e Variedades. Aracaju, 04/01/2004.

${ }^{18}$ CINFORM, Cultura e Variedades. Aracaju, 18/01/2004.

${ }^{19}$ POLLAK, Michel. Memória, esquecimento, silêncio. Estudos históricos, Rio de Janeiro: CPDOC/FGV, v. 2, n. 3, 1989, p. 3.

${ }^{20}$ CINFORM, Cultura e Variedades. Aracaju, 18/01/2004.

${ }^{21}$ DELGADO, Andréa Ferreira. Goiás: a invenção da cidade "Patrimônio da Humanidade. Horizontes Antropológicos, Porto Alegre, ano 11, n. 23, p. 113-143, jan./jun. 2005, p. 131.

${ }^{22}$ Ver: http://www.japaratuba.se.gov.br/

${ }^{23}$ Disponível em: (http://www.japaratuba.se.gov.br/biografia_bispo.htm. Acesso em 10/05/2009).

${ }^{24}$ ENDERS, Armelle. "O Plutarco brasileiro": A produção dos vultos nacionais no Segundo Reinado. Estudos Históricos, v. 25, 2000, p. 46.

${ }^{25}$ LE GOFF, Jacques. História e memória. São Paulo: UNICAMP, 2006, p. 526.

${ }^{26}$ DOSSE, François. O desafio biográfico. Escrever uma vida. São Paulo: Edusp, 2009, p. 123.

${ }^{27}$ CINFORM, Cultura e Variedades. Aracaju, 20/07/2003.

${ }^{28}$ Arthur Bispo do Rosário está voltando. CINFORM, Cultura e Variedades. Aracaju, 04/01/2004.

${ }^{29}$ LE GOFF, Jacques. História e memória. São Paulo: UNICAMP, 2006, p. 526.

${ }^{30}$ Arthur Bispo do Rosário está voltando. CINFORM, Cultura e Variedades. Aracaju, 04/01/2004.

${ }^{31}$ NORA, Pierre. Entre memória e história. A problemática dos lugares. Projeto História, São Paulo, n. 10, 1993, p. 22.

${ }^{32}$ As entrevistas citadas são foram extraídas do Programa Ação, de 21 de novembro de 2009, disponível em: http://acao.globo.com/Acao/0,23167,GTS0-3776-338107,00.html

${ }^{33}$ Conselho Consultivo do Iphan aprova o registro da Renda Irlandesa (SE). Disponível em: http://portal.iphan.gov.br/portal/baixaFcdAnexo.do?id=968. Acesso em: 22/01/2010.

${ }^{34}$ Arthur Bispo do Rosário, a glória tardia. Aracaju Magazine, Aracaju, 01/07/2003.

${ }^{35}$ CINFORM, Cultura e Variedades. Aracaju, 20/07/2003.

${ }^{36}$ CINFORM, Cultura e Variedades. Aracaju, 18/01/2004.

${ }^{37}$ HUYSSEN, Andreas. Seduzidos pela memória. Rio de Janeiro: Aeroplano, Universidade Cândido Mendes, Museu de Arte Moderna do Rio de Janeiro, 2000, p. 9.

${ }^{38}$ HIDALGO, Luciana. Arthur Bispo do Rosário - O senhor do labirinto. Rio de Janeiro: Rocco, 1996. 
${ }^{39}$ www.jornaldacidade.net. Acesso em 10/02/2009.

${ }^{40}$ Disponível em: www.infonet.com.br. Acesso em 10/12/2009.

${ }^{41}$ ABREU, Regina. Entre a nação e a alma: quando os mortos são comemorados. Estudos Históricos, Rio de Janeiro, vol. 7, n. 14, 1994, p. 4.

${ }^{42}$ Idem. Ibidem, p. 4.

${ }^{43}$ DELGADO, Andréa Ferreira. Goiás: a invenção da cidade "Patrimônio da Humanidade. Horizontes Antropológicos, Porto Alegre, ano 11, n. 23, p. 113-143, jan./jun. 2005, p. 46.

${ }^{44}$ TEDESCO, João Carlos. Nas cercanias da memória. Temporalidade, experiência e narração. Passo Fundo: UPF; Caxias do Sul: UCS, 2004, p. 79.

${ }^{45}$ NORA, Pierre. Entre memória e história. A problemática dos lugares. Projeto História, São Paulo, n. 10, 1993, p. 31. 